\title{
Analysis of Carbon Nanotubes Produced by Pyrolysis of Composite Film of Poly (Vinyl Alcohol) and Modified Fly Ash
}

\author{
Dilip C. D. Nath*, Veena Sahajwalla \\ Centre for Sustainable Materials Research and Technology, School of Materials Science and Engineering, The University of New \\ South Wales, Sydney, Australia. \\ Email: *dilip.nath@unsw.edu.au
}

Received December $4^{\text {th }}, 2011$; revised January $24^{\text {th }}, 2012$; accepted February $1^{\text {st }}, 2012$

\begin{abstract}
We determined the catalytic function of chemically modified fly ash (MFA) for the growth of carbon nanotube (CNT) ropes with $\sim 54 \%$ yield by the pyrolysis of the composite film of poly (vinyl alcohol) (PVA) at $500^{\circ} \mathrm{C}$ for 10 min under $2 \mathrm{~L} / \mathrm{min}$ flow of nitrogen. Fly ash was treated with $2 \mathrm{M}$ sodium hydroxide to have MFA and used with PVA to fabricate the composite film by aqua casting. CNT was analyzed using SEM, TEM, XPS and Raman spectroscopy. The growths of CNT on MFA surfaces were visualized with different geometric self-assembly, e.g., bundles of CNT in ropes, twisted ropes, Y-branch ropes and staked-cone sheet. Thus, the mixtures of CNT ropes and MFA are a potential filler material for fabricating composites with polymer and metal.
\end{abstract}

Keywords: Poly (Vinly Alcohol); Fly Ash; Carbon Nanotube and Self-Assembly

\section{Introduction}

Self-assembled carbon nanotubes (CNTs) have the potential for a wide range of applications, among them devices for energy storage and energy conversion, composites with metal and polymer, electrodes, and catalyst supports [1]. The synthesis and processing of CNTs are challenging tasks for designing self-assembled carbon nanostructured materials. Self-assembled knots of CNT ribbons by dispersion in the solutions of sodium dodecyl sulphate (SDS) and PVA have been reported [2].

Ongoing research into the production of assemblies of aligned CNT films has been directed towards achieving uni-directional and multi-directional orientations. The established method focuses on post-processing CNTs grown by an arc-discharge or a CVD method. The homogeneous dispersion/solution of CNT in oleum has been used to fabricate an isotropic film exhibiting fibrillar morphology by leaching and drying [3]. A similar approach has been used in the fabrication of individual CNT fiber blending with polymer solution/gel [2,4]. CNT threads have also been prepared on a silicon substrate as a result of van der Waal interactions from an aligned assembly. The CVD of hexane and thiophene in the presence of the ferrocene catalyst has been shown to produce and isolate CNT fiber strands [5].

*Corresponding author.
In the pyrolysis method, benzene at $1000^{\circ} \mathrm{C}$ over $\mathrm{Ni}$ powder for $60 \mathrm{~min}$ generated different types of carbon nanostructures [6]. Carbon nanocapsules with silicon carbide nanoparticles were reported by thermal decomposition of PVA at $500^{\circ} \mathrm{C}$ in argon [7]. Catalytic graphitization was described using PVA with an iron-containing catalyst for the formation of CNTs at $600^{\circ} \mathrm{C}-800^{\circ} \mathrm{C}$ in nitrogen flow for $2 \mathrm{~h}$. The catalyst particles were uniformly distributed on the surface and filled the hollow channel of CNTs. The CNT structures depended on the nature of the catalyst and carbon sources as well as the pyrolysis conditions [8].

Coal combustion in power stations generates huge amounts of FA as a by-product. The storage and proper disposal of this material are a significant global concern on both environmental and economic fronts [9]. FA is commonly processed by disposal as landfill in dams and lagoons. It typically consists of crystalline aluminosilicate, mullite and $\alpha$-quartz $(\sim 96.5 \%)$ spherical particles between $1 \mu \mathrm{m} \sim 100 \mu \mathrm{m}$ in diameter, along with traces of metal oxides ( $3.5 \%)$ (iron, calcium, magnesium, potassium, sodium, titanium), depending on the processing condition and the chemical composition of the coal burned [10].

In 2007 , less than $20 \%$ of 14.5 million tons produced in Australia was re-used [11]. Successful results have been achieved in the use of FA of different researchers 
are in agriculture and soil management, the production of polymer composites [10] cement and concrete [12], metal composites [13] as catalytic support for hydrogen production, steam methane reforming [9] and iron-nitrate-impregnated support for the synthesis of multi-walled CNTs (MWCNTs) [11].

Research on the recycling of FA as a filler and catalyst support has been moving towards a green technology for value-added products and composite materials. There have been no published reports on the use of FA as filler in PVA composite for enhancing mechanical properties and as catalyst alone for synthesising CNT ropes of different self-assembled geometric structures. We have recently reported the dual functions of fly ash as filler and catalyst for the synthesis of CNT materials [14]. The preliminary data on the role of synthesis of CNT material using the chemically modified fly ash was reported [15]. We report here further analysis of synthesized CNT materials using $\mathrm{X}$-ray photoelectron spectroscopy (XPS).

\section{Materials and Methods}

\subsection{Materials and Preparation of Composite Films}

An industrial waste FA material was obtained from Swanbank Coal Fire Plant, Qld, Australia. The PVA (molecular weight, $125,000 \mathrm{~g} / \mathrm{mol}$; degree of hydrolysis $\sim 89 \%$ with remaining $11 \%$ acetate) from S.D. Fine-Chemical Ltd, Chennai, India, and reagent grade sodium hydroxide from Laboratory Unilab Reagent, Sydney, were purchased and used as received.

The detailed modification process of FA with sodium hydroxide at $85^{\circ} \mathrm{C}$ for $8 \mathrm{~h}$ was reported in our earlier research. The PVA composite film was fabricated by a casting method from an aqueous suspension of PVA and FA. The PVA was dissolved in distilled water at $80^{\circ} \mathrm{C}$ for $2 \mathrm{~h}$ to prepare the $1.2 \mathrm{wt} \%$ solution. The FA particles (5 wt $\%$ ) were dispersed and sonicated for $5 \mathrm{~min}$. The resulting mixture was cast in glass petri dishes $(100 \mathrm{~mm}$ diameter) and bubbles were removed by shaking and air blowing. The petri dishes were kept at room temperature until completely dry. The films were peeled out and dried in an oven at $60^{\circ} \mathrm{C}$ under vacuum for $6 \mathrm{~h}$. The thickness of the films was $50 \mu \mathrm{m}-70 \mu \mathrm{m}[10]$.

\subsection{Pyrolysis Method}

The pyrolysis of the samples was run at an isothermal condition in a horizontal quartz tube furnace (HTF 6035) under nitrogen flow. The hot zone of the furnace was preheated to $500^{\circ} \mathrm{C}$ using thermocouple. The furnace connection scheme was as reported in our work [14]. The weighed amount of sample was kept in an alumina crucible and placed on a graphite feeder, which was inserted into the cold zone with simultaneous nitrogen purging at 2 $\mathrm{L} / \mathrm{min}$, held for $30 \mathrm{~s}$, and passed through into the hot zone for $10 \mathrm{~min}$. After pyrolysis, the sample was relocated from hot to cold zones via the graphite feeder for $30 \mathrm{~s}$ and removed from the alumina crucible at room temperature. The sample was stored in a small bottle, and used for calculation and analysis.

\subsection{Analysis and Analytical Instruments}

A Hitachi 4500-II scanning electron microscope (SEM) was used to examine the morphology of the sample. The sample on carbon tape was coated with chromium in a chromium sputter unit to improve conductivity. Transmission electron microscopy (TEM) images were obtained using a Philips CM200 with $200 \mathrm{kV}$. The sample was dispersed in ethanol and a drop of diluted suspension was poured onto a carbon-coated copper grid, which was directly injected into a sample injection holder after air-drying for three days.

XPS was conducted using an ESCALAB220i-XL (VG Scientific, Thermo Scientific, UK) to calculate the atomic composition of the CNTs. The standard conditions were used: $>2 \times 10^{-9}$ mbar, mono-chromated AlK alpha (energy $1486.6 \mathrm{eV}), 200 \mathrm{~W}(20 \mathrm{~mA}$ and $10 \mathrm{kV})$, spot size $\sim 1 \mathrm{~mm}$ in cross, photoelectron take-off angle of 90 , pass energy of $100 \mathrm{eV}$ for survey scans and $20 \mathrm{eV}$ for region scans, and step-sizes of $1 \mathrm{eV}$ for survey scans and $0.1 \mathrm{eV}$ for region scans. Raman spectroscopy was performed on an inVia Reinshaw Raman microscope using green laser excitation $(514 \mathrm{~nm})$ for the calculation of the degree of ordered CNT structures. Scan was recorded on an extended range $\left(100 \mathrm{~cm}^{-1}-4000 \mathrm{~cm}^{-1}\right)$, with $10 \%$ power of $1.2 \mathrm{~mW}$. The samples were prepared by pressing onto a glass slide.

\section{Results and Discussion}

Powder PVA, MFA, the physical mixtures of powder PVA and MFA, PVA film, and composite film were pyrolized at $500^{\circ} \mathrm{C}$ for $10 \mathrm{~min}$ under $2 \mathrm{~L} / \mathrm{min}$ nitrogen flow. The solid carbonaceous residues were collected and calculated (Table 1); however, the gaseous extract was not analyzed by GC/MS, but was exhausted as flu gas, since there are several studies on the analysis of gaseous extract of pyrolysis of PVA under nitrogen.

The products were formed by depolymerization, dehydration and intramolecular cyclization reactions of polyene sequences; this accounted for the formation of aromatic products in the absence of a catalyst [16]. The hydrocarbons mainly consisted of C6 compounds (gasoline, diesel oil, and aromatics); the gaseous composition was $40.4 \mathrm{wt} \% ; \mathrm{H}_{2} \mathrm{O} 20.9 \mathrm{wt} \%, \mathrm{CO}_{2} 19.2 \mathrm{wt} \%$, and $\mathrm{CO}$ $18.9 \mathrm{wt} \%$ relative to the total mass of the gaseous products [16]. 
Table 1. Pyrolysis of PVA and composite film with MFA*.

\begin{tabular}{ccccccc}
\hline Entry No. & Powder PVA (g) & MFA (g) & Composite film (g) & Solid residue (g) & Yield (\%) & Estimated CNT yield on PVA (\%) \\
\hline 1 & - & - & 0.13 & 0.07 & 53.8 & 43.1 \\
2 & 0.13 & - & - & 0.00 & 0 & 0 \\
3 & - & - & 0.13 (PVA film) & 0.00 & 0 & n.d. \\
4 & 0.13 & 0.03 & - & Trace (MFA) & n.d. & - \\
\hline
\end{tabular}

${ }^{*}$ All experiments were performed at $500^{\circ} \mathrm{C}$ for $10 \mathrm{~min}$.

The pyrolysis of PVA composite film with $5 \mathrm{wt} \%$ modified FA left behind black solid residue on the alumina crucible. The yield was $53.8 \%$ on the basis of film weight and solid residue. There was no carbonaceous residue from the pyrolyis of powder PVA or even the physical mixtures of powder PVA and modified FA, due to the transformation of PVA into volatile compounds by degradation under similar conditions. The macroscopic contact of PVA and MFA by physical mixing provided has no opportunity for the formation of transitional bonding between functional groups in the mixtures. The transitional intimate contact area was a prerequisite which was considered an active site for the formation of carbonaceous material.

The existing transitional bonding in the composite film accelerated the dehydrogenation and dehydration reactions in PVA chains leaving C-C fragments. The microscopic intimate contact areas were visualized in the SEM image of the fractured-surface film in the tensile tests [10]. The interfacial interaction was thus established as a crucial factor for enhancing the mechanical strength and formation of catalytic active sites for the growth of carbonaceous solid residue on FA surfaces. The morphology of the solid residue was visualized and analyzed by SEM and TEM as CNT ropes.

The representative SEM images of the different geometric morphologies of CNT ropes are presented in Figures 1(a)-( f). Figure 1(a) clearly shows the active site where CNT ropes were initiated and grown randomly with curved and entangled structures on the FA surfaces. Figure 1(b) shows several isolated, long, flexible CNT ropes along with spherical-shaped carbon fullerene captured with a $500 \mu \mathrm{m}$ scale bar. Similar results of fullerene formation were achieved using transition metal catalyst. The comparable sizes of the round-shaped fullerenes were 60 carbons - 100 carbons [17]. The widths appear to be constant over the whole length of the ropes. The total carbon number of fullerenes produced was not yet determined. Figure 1(c) reveals a section of the isolated rope, with higher magnification of the defect area, where the tunnel of the nanotube is partially evident. Fi- gure 1(d) is of a single hook-shaped CNT rope attached with small rope in the middle of the section. Figure 1(e) shows a section of the long-ordered self-assembled twisted ropes.

The self-assembly of two, three and complicated knitted CNT ropes also appeared in the multidirectional pathways. Figure 1(f) shows the section of Y-branch structure of CNT ropes. No effects of higher temperature, FA concentration and time on the growth and structure of CNT ropes were observed in the system. The surfaces of CNT ropes were not absolutely free from FA particles. There was FA particle adherence to some areas of the CNT ropes, suggesting 1) defects in graphitization permitted by the presence of space/void for MFA particle deposition, and/or 2) the presence of functionalized carbon, which strongly interacts with MFA.

Different types of CNT geometry, e.g. cylindrical, spindle-shaped, constrained, Y-branch structure, bamboo-shaped and spiral structures were produced by the pyrolysis of benzene and hydrogen at $1100^{\circ} \mathrm{C}[18,19]$. We presented a simple and in-situ environmentally friendly method for self-assembled CNT ropes with indefinitely long and highly flexible permanent twisted microscopic structures. Figure 2 shows the representative TEM images of CNT ropes structures.

The diffraction pattern of the selected area electron diffraction (SAED) experiment is shown in the inset of Figure 2 as a representative data for further study. The diffraction spots were sharp and aligned, indicating a highly ordered arrangement of CNT in rope. Bundles of CNT in the form of ropes [20] have been reported by an expensive CVD method. We observed the appearance of unrolled graphene and incomplete cone-shaped CNT sheets in the system. The variations of pyrolysis temperature up to $1000^{\circ} \mathrm{C}$ for $60 \mathrm{~min}$ showed no effect on yield and structural configuration. We found no MWCNT in any of our TEM images.

XPS analysis was performed to evaluate the atomic concentration and carbon functionality at the CNT surfaces. The details of our data on chemical compositions and full-width half-maximum (FWHM) of peaks of CNTs 

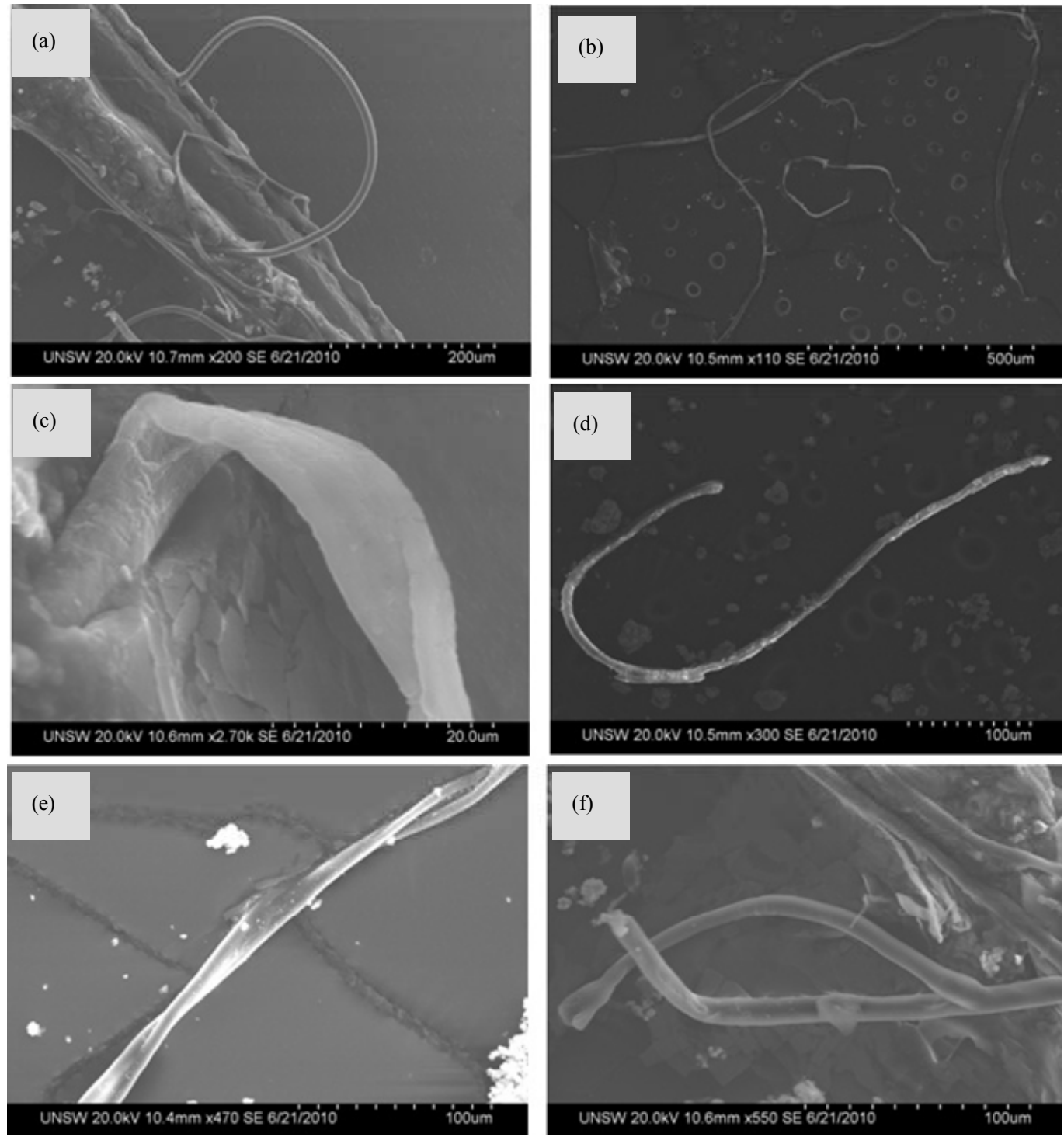

Figure 1. Representative SEM images of SWCNT ropes: (a) Random growth on active sites with curved and entangled geometry; (b) Isolated flexible ropes grown on MFA surfaces along with round-shaped fullerenes; (c) Higher magnification of section of rope showing defect; (d) Hook-shaped single rope; (e) Twisted ropes; And (f) a section of Y-branch structure in a rope.

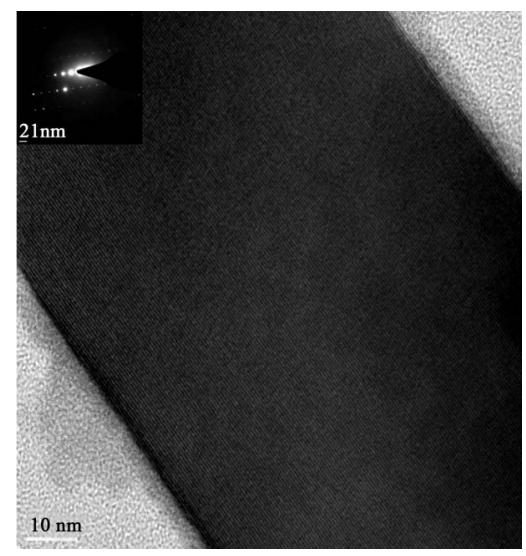

Figure 2. TEM images of higher magnification of a straight rope showing a SWCNT bundle with diffraction patterns. along with FA are summarized in Table 2. All peaks were identified using information from the XPS handbook [21].

The peaks at 285.1 and $532.2 \mathrm{eV}$ were generated by photoelectrons emitted from the carbon $1 \mathrm{~s}$ and oxygen $1 \mathrm{~s}$ core levels, respectively. Therefore, it can be assumed that oxygen is a component of CNTs. The intensity of the oxygen 1s core level was much higher than those of the $\mathrm{Si}$ and $\mathrm{Al} 2 \mathrm{~s}$ core levels. The relative concentration of oxygen and carbon are nearly $18 \%$ and $74 \%$, respectively; the remainder consisted of mixtures of $\mathrm{Na}, \mathrm{Si}, \mathrm{Ca}$ and $\mathrm{Al}$ in the CNT sample. However, the percentages of $\mathrm{O}, \mathrm{Si}$ and $\mathrm{Al}$ were $\sim 60.2 \%, 25 \%$ and $6 \%$, respectively, including $4 \%$ unburned carbon in FA, which was of amorphous structure. 
Table 2. Lists of XPS peaks of CNT and MFA.

\begin{tabular}{|c|c|c|c|c|c|c|c|c|c|c|}
\hline \multicolumn{4}{|c|}{ CNT sample } & \multicolumn{3}{|c|}{ MFA sample } & \multicolumn{4}{|c|}{ Detailed C $1 \mathrm{~s}$ peak } \\
\hline Core level & Peak (eV) & FWHM (eV) & Atm $(\%)$ & Peak (eV) & FWHM (eV) & Atm $(\%)$ & Core level & Peak (eV) & FWHM $(\mathrm{eV})$ & $\operatorname{Atm}(\%)$ \\
\hline $\mathrm{Al} 2 \mathrm{p}$ & 75.2 & 2.1 & 0.7 & 74.1 & 1.6 & 5.5 & $\mathrm{C}-\mathrm{C} / \mathrm{C}-\mathrm{H}$ & 285.1 & 1.2 & 83.8 \\
\hline Si $2 p$ & 103.1 & 3.1 & 4.1 & 102.9 & 1.8 & 24.9 & $\mathrm{C}-\mathrm{O}-\mathrm{H}$ & 286.6 & 1.2 & 6.8 \\
\hline $\mathrm{C} 1 \mathrm{~s}$ & 285.1 & 3.1 & 73.8 & 284.8 & 2.1 & 4.1 & $\mathrm{C}-\mathrm{O}-\mathrm{C}$ & 288.1 & 1.2 & 4.1 \\
\hline $\mathrm{Ca} 2 \mathrm{p}$ & 348.1 & 1.9 & 0.6 & 347.7 & 0.8 & 0.2 & $\mathrm{C}=\mathrm{O}$ & 289.2 & 1.2 & 3.6 \\
\hline $\mathrm{O} 1 \mathrm{~s}$ & 532.2 & 3.7 & 18.3 & 532.6 & 1.8 & 59.2 & $\mathrm{O}-\mathrm{C}=\mathrm{O}$ & 290.7 & 1.2 & 1.6 \\
\hline $\mathrm{Na} 1 \mathrm{~s}$ & 1072.1 & 3.2 & 1.5 & 1073.5 & 2.5 & 3.6 & & & & \\
\hline
\end{tabular}

Figure 3 shows the region of XPS carbon spectra along with curve-fitting by the Lorentzian method. The whole spectrum is also shown inset in Figure 3. The extended region shows a broad area in the higher binding energy region. The broad peak was isolated by the Lorentzian method to divide and fit the curve by composed of five peaks. The peak at $285.1 \mathrm{eV}$ was generated by the excitation of $\mathrm{C}-\mathrm{C} / \mathrm{C}-\mathrm{H}$ bonds in the graphite configuretion with $\sim 83.8 \%$, including its shake-up structure. The peak was centred at $286.6 \mathrm{eV}$, which can be attributed to photoelectrons emitted from carbon atoms bonding with $\mathrm{C}-\mathrm{O}-\mathrm{H}$ group configuration with $6.8 \%$.

Three other small peaks were centred at 288.1, 289.2 and $290.7 \mathrm{eV}$, emitted from the carbon atoms belonging to $\mathrm{C}-\mathrm{O}-\mathrm{C}(4.1 \%), \mathrm{C}=\mathrm{O}(3.6 \%)$ and $-\mathrm{COOH} /-\mathrm{COOCH}_{3}$ $(1.6 \%)$ groups, respectively. As discussed before, oxygencontaining functional groups grafted at CNT are likely to have been the precursors of the acetate nucleation sites in the PVA backbones. The different types of functionalized carbons are bridged in CNT graphite sheets by other systems and validated with XPS spectra $[3,22]$.

The graphitic configurations of CNT ropes were analyzed by Raman spectroscopy for more reliable authenticcation of the carbon structure. The characteristic peaks were identified and shown in Figure 4 on excitation with $514 \mathrm{~nm}$ laser light. The strongest Raman $\mathrm{G}$ band line, the characteristic peak for well-graphitised CNT, appeared at $1598 \mathrm{~cm}^{-1}$ with relatively narrower FWHM, $71 \mathrm{~cm}^{-1}$.

Another peak at $1380 \mathrm{~cm}^{-1}$ with $112 \mathrm{~cm}^{-1} \mathrm{FWHM}$ is the D-line band, indicating a typical sign for defective graphitic structures on CNT. The intensity of the D-line is lower than that of the G-line, evidence of the more ordered carbon structure in CNT. CNT ropes consist mainly of crystalline graphitic carbons along with amorphous carbons. The intensity of isolated peaks was calculated and used to determine the characteristic features of the graphitic wall of CNT ropes [11].

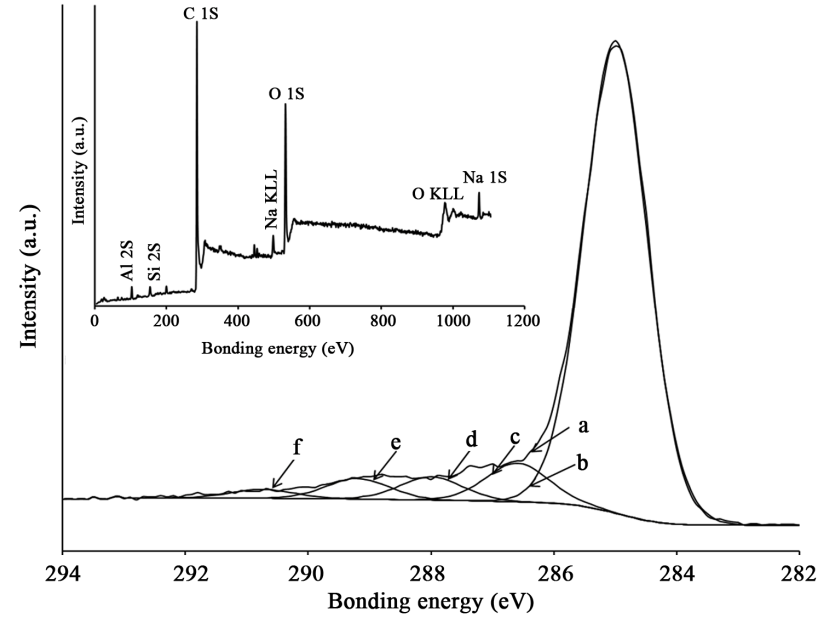

Figure 3. Extended peak of $C$ 1s from a wide-range XPS spectrum of CNT: 1) original raw peak; 2) C-C/C-H bonds configuration; 3) C-O- configuration; 4) C-O-C configuration; 5) $\mathrm{C}=\mathrm{O}$ configuration; 6) $-\mathrm{COOH} /-\mathrm{COOCH}_{3}$ configuration and the whole spectrum in inset.

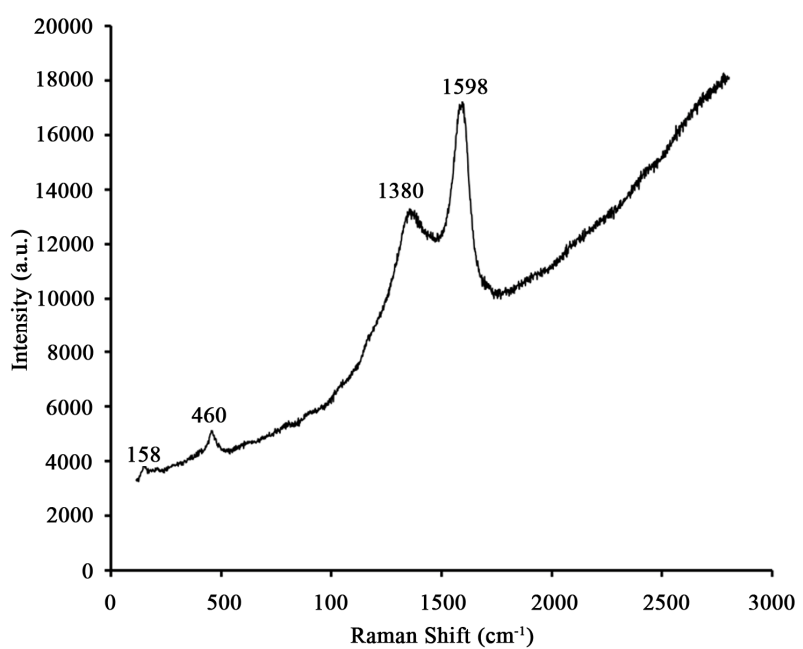

Figure 4. Raman spectrum of CNT. 
The intensity ratio $(I \mathrm{G} / I \mathrm{D})$ of the $\mathrm{G}$ band and $\mathrm{D}$ band was treated to determine the degree of carbon graphitization in CNT configurations. The higher $I \mathrm{G} / I \mathrm{D}$ ratio indicated a greater degree of wall graphitization, suggesting superior CNT quality. The $I \mathrm{G} / I \mathrm{D}$ ratio of the CNT ropes grown on FA surfaces was 3.43, higher than the 1.17 for MWCNTs yielded for iron-catalyst-coated FA by the CVD method [11]. The line width and intensity ratio of $(I \mathrm{G} / I \mathrm{D})$ varied depending on the structure of the carbons and the conditions used for analysis, e.g., laser power and energy [23]. The well-known phenomenon, Raman band intensities and widths, increased with the decrease of wavelength of exciting laser, whereas these lines were shifted to lower wave number regions with an increase of the exciting laser power [24].

The intensity ratios of the lines D and G decreased nonlinearly with the increasing of laser energy, depending on the types of tubes and graphite crystallites. The broadening of the bands relates to the defect and curvature of the CNT ropes because of the enhancement of the electron-phonon coupling [22]. The increase of electron-phonon coupling generally results from the admixture of $\mathrm{sp}^{3}$ to $\mathrm{sp}^{2}$ bonded carbon atoms [23]. The overlapping peaks of silica of FA and radial breathing mean (RBM) of CNT ribbons were observed in the regions lower than $<500$ $\mathrm{cm}^{-1}$.

In term of growth mechanism, several models have been proposed by the decomposition of hydrocarbon on metal surfaces [8,22], although the exact modes of action are still hypothetical. The mechanism of CNT growth was studied with respect to carbon dissolution in a metal catalyst. The dissolved carbon produced by the decomposing of PVA at temperatures $600^{\circ} \mathrm{C}-800^{\circ} \mathrm{C}$ by an intermediate reaction on the catalyst surface, iron oxide. The dissolved carbon diffused through the metallic particle to form the layers of the growing CNT. For this reason, metallic particles were present at the ends of the CNT [8].

Considering the results obtained in the pyrolysis of PVA composite with unmodified FA, we have recently proposed a plausible overall growth mechanism for CNT structure [25]. A building block mechanism was considered with a broken TEM image of CNT to define a hypothetical model [25]. We observed the deposition of different sizes building blocks nearby on the broken edge of the tube in TEM image by exposure of sonication and high intense of electron beam. The different sizes of the broken building blocks were inferred from the results of different degrees of polymerization of PVA, since each of the PVA chains forms a building block in CNT structure [25]. We believe CNTs from the pyrolysis of PVA composite film with chemically modified FA also formed followed by similar mechanism.

\section{Conclusion}

CNTs grown on MFA surfaces were visualized with different self-assembly, e.g., bundles of CNT in ropes, twisted ropes, Y-branch ropes and staked-cone sheet. The material of self-assembled CNT ropes with MFA therefore is considered as potential reinforcing filler in the field, for large-scale application with polymer for the composites. The partially functionalized CNT materials e.g., $\mathrm{C}-\mathrm{O}-\mathrm{H}(6.8 \%), \mathrm{C}-\mathrm{O}-\mathrm{C}(4.1 \%), \mathrm{C}=\mathrm{O}(3.6 \%)$ and $-\mathrm{COOH} /$ $-\mathrm{COOCH}_{3}(1.6 \%)$, have another merit for making hybrid bridges by covalent reactions with organic polymers for new classes of materials.

\section{REFERENCES}

[1] R. H. Baughman, A. A. Zakhidov and W. A. D. Heer, "Carbon Nanotubes the Route toward Applications," Science, Vol. 297, No. 5582, 2002, pp. 787-792.

doi:10.1126/science. 1060928

[2] B. Vigolo, A. Penicaud, C. Coulon, C. Sauder, R. Pailler, C. Journet, P. Bernier and P. Poulin, "Macroscopic Fibers and Ribbons of Orientated Carbon Nanotubes," Science, Vol. 290, No. 5495, 2000, pp. 1331-1334. doi:10.1126/science.290.5495.1331

[3] T. V. Sreekumar, T. Liu, S. Kumar, L. M. Ericson, R. H. Hauge and R. E. Smalley, "Single-Wall Carbon Nanotube Films," Chemistry of Materials, Vol. 15, No. 1, 2003, pp. 175-178. doi:10.1021/cm020367y

[4] A. B. Dalton, S. Collins, E. Munoz, J. M. Razal, V. H. Ebron, J. P. Perraris, J. N. Coleman, B. G. Kim and R. H. Baughman, "Super-Tough Carbon-Nanotube Fibres," $\mathrm{Na}$ ture, Vol. 423, 2003, pp. 703-703. doi:10.1038/423703a

[5] B. Wei, R. Vajtai, Y. Y. Choi and P. M. Ajayan, "Structural Characterizations of Long Single-Walled Carbon Nanotube Strands," Nano Letter, Vol. 2, No. 10, 2002, pp. 1105-1107. doi:10.1021/n1025719e

[6] M. Benito, Y. Maniette, Y. Aniette, E. Mogoza and T. M. Martnez, "Carbon Nanotubes Production by Catalytic Pyrolysis of Benzene," Carbon, Vol. 36, No. 5-6, 1998, pp. 681-683. doi:10.1016/S0008-6223(98)00039-6

[7] T. Oku, K. Niihara and K. Suganuma, "Formation of Carbon Nanocapsules with SiC Nanoparticles Prepared by Polymer Pyrolysis," Journal of Materials Chemistry, Vol. 8, No. 6, 1998, pp. 1323-1325. doi:10.1039/a801912f

[8] O. P. Krivoruchko, N. I. Maksimova, V. I. Zaikovskii and A. N. Salanov, "Study of Multiwalled Graphite Nanotubes and Filaments Formation from Carbonized Products of Polyvinyl Alcohol via Catalytic Graphitization at $600^{\circ} \mathrm{C}-800^{\circ} \mathrm{C}$ in Nitrogen Atmosphere," Carbon, Vol. 38, No. 7, 2000, pp. 1075-1082. doi:10.1016/S0008-6223(99)00225-0

[9] S. Wang, "Application of Solid Ash Based Catalysts in Heterogeneous Catalysis," Environmental Science and Technology, Vol. 42, No. 19, 2008, pp. 7055-7063. doi: $10.1021 / \mathrm{es} 801312 \mathrm{~m}$ 
[10] D. C. D. Nath, S. Bandyopadhyay, A. Yu, D. Blackburn and C. White, "High Strength Bio Composite Films of Poly (Vinyl Alcohol) Reinforced with Chemically Modified-Fly Ash," Journal of Materials Science, Vol. 45, No. 5, 2010, pp. 1354-1360. doi:10.1007/s10853-009-4091-6

[11] O. M. Dunens, K. J. Mackenzie and A. T. Harris, "Synthesis of Multiwalled Carbon Nanotubes on Fly Ash Derived Catalysts," Environmental Science and Technology, Vol. 43, No. 20, 2009, pp. 7889-7894. doi:10.1021/es901779c

[12] J. P. Gorninski, D. C. D. Molin and C. S. Kazmierczak, "Study of the Modulus of Elasticity of Polymer Concrete Compounds and Comparative Assessment of Polymer Concrete and Portland Cement Concrete," Cement \& Concrete Research, Vol. 34, No. 11, 2004, pp. 2091-2095. doi:10.1016/j.cemconres.2004.03.012

[13] P. K. Rohatgi, N. Gupta and S. Alaraj, "Thermal Expansion of Aluminum-Fly Ash Cenosphere Composites Synthesized by Pressure Infiltration Technique," Journal of Composite Materials, Vol. 40, No. 13, 2006, pp. 11631173. doi: $10.1177 / 0021998305057379$

[14] D. C. D. Nath and V. Sahajwalla, "Application of Fly Ash as a Catalyst for Synthesis of Carbon Nanotube Ribbons," Journal of Hazardous Materials, Vol. 192, No. 2, 2011, pp. 691-697. doi:10.1016/j.jhazmat.2011.05.072

[15] D. C. D. Nath and V. Sahajwalla, "Growth of Carbon Nanotubes by Pyrolysis of Composite Film of Poly (Vinyl Alcohol) and Modified Fly Ash," Materials Science and Applications, 2011, ID: 7700662.

[16] J. L. Shie, Y. H. Chen, C. Y. Chang, J. P. Lin, D. J. Lee and C. H. Wu, "Thermal Pyrolysis of Poly (Vinyl Alcohol) and Its Major Products," Energy \& Fuels, Vol. 16, No. 1, 2002, pp. 109-118. doi:10.1021/ef010082s

[17] D. S. Bethune, C. H. Klang, M. S. de Varies, G. Gorman, R. Savory, J. Vazquez and R. Beyers, "Cobalt-Catalysed Growth of Carbon Nanotubes with Single-Atomic-Layer Walls," Nature, Vol. 363, No. 6430, 1993, pp. 605-607. doi: $10.1038 / 363605 \mathrm{a} 0$
[18] A. Oberlin, M. Endo and T. Koyama, "Filamentous Growth of Carbon through Benzene Decomposition," Journal of Crystal Growth, Vol. 32, No. 3, 1976, pp. 335349. doi:10.1016/0022-0248(76)90115-9

[19] L. Ming, P. Joyce, T. Ying, B. Chris, P. Kian, E. Loh, T. Soon and F. Yong-Lim, "Dynamical Observation of Bamboo-Like Carbon Nanotube Growth," Nano Letter, Vol. 7, No. 8, 2007, pp. 2234-2238. doi:10.1021/n1070681x

[20] C. B. Liu, H. M. Cheng, H. T. Cong, F. Li, G. Su, B. L. Zhou and M. S. Dresselhaus, "Synthesis of Macroscopically Long Ropes of Well-Allinged Single-Walled Carbon Nanotubes," Advanced Materials, Vol. 12, No. 16, 2000, pp. 1190-1192. doi:10.1002/1521-4095(200008)12:16<1190::AID-ADM A1190>3.0.CO;2-C

[21] J. E. Moulder, W. F. Stickle, P. E. Sobol and K. D. Bomben, "Handbook of X-Ray Photoelectron Spectroscopy," Perkin Elmer Corporation, Waltham, 1992.

[22] A. A. Didik, V. I. Kodolov, A. Y. Volkov, E. G. Volkova and K. H. Hallmeier, "Low-Temperature Growth of Carbon Nanotubes," Inorganic Materials, Vol. 39, No. 6, 2003, pp. 583-587. doi:10.1023/A:1024045002419

[23] J. Kastner, T. Pichler, H. Kuzmany, S. Curran, W. Blau, D. N. Weldon, M. Delamesiere, S. Draper and H. Zandbergen, "Resonance Raman and Infrared Spectroscopy of Carbon Nanotubes," Chemical Physics Letter, Vol. 221, No. 1-2, 1994, pp. 53-58. doi:10.1016/0009-2614(94)87015-2

[24] Y. Ando, X. Zhao and H. Shimoyama, "Structure Analysis of Purified Multiwalled Carbon Nanotubes," Carbon, Vol. 39, No. 4, 2001, pp. 569-574. doi:10.1016/S0008-6223(00)00162-7

[25] D. C. D. Nath and V. Sahajwalla, "Growth Mechanism of Carbon Nanotube Produced by Pyrolysis of a Composite Film of Poly (Vinyl Alcohol) and Fly Ash," Applied Physics A, Vol. 104, No. 2, 2011, pp. 539-544. doi:10.1007/s00339-011-6405-1 